\title{
Standard Tibetan Language
}

National Cancer Institute

\section{Source}

National Cancer Institute. Standard Tibetan Language. NCI Thesaurus. Code C153862.

A Sino-Tibetan language that is an official language of the Tibet Autonomous Region of the People's Republic of China. 